Supporting Information

\title{
Water-Soluble, Cyclodextrin-Modified CdSe-CdS Core-Shell Structured Quantum Dots
}

\section{Kumaranand Palaniappan, Cuihua Xue, Ganesh Arumugam,} Stephen A. Hackney, Jian Liu ${ }^{*}$

- TEM of $\beta-C D / C d S e$

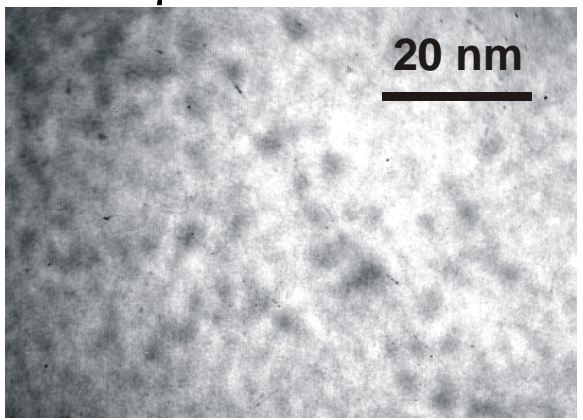

- Size distribution of $\beta-\mathrm{CD} / \mathrm{CdSe}$

Size distribution of $\beta-\mathrm{CD} / \mathrm{CdSe}$

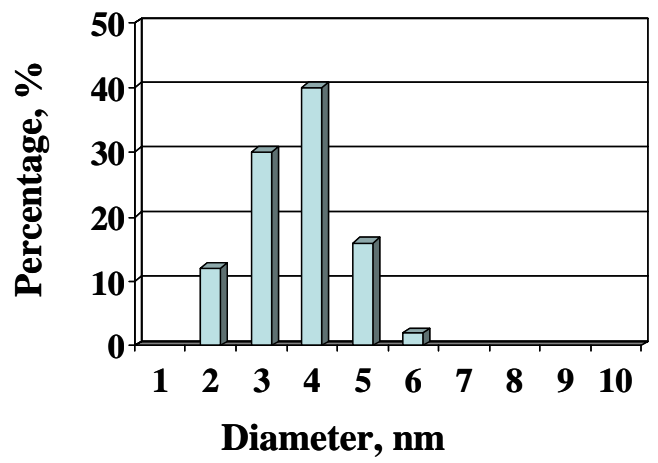

- Size distribution of $\beta-\mathrm{CD} / \mathrm{CdSe}-\mathrm{CdS}$

Size distribution of $\beta-C D / C d S e-C d S$

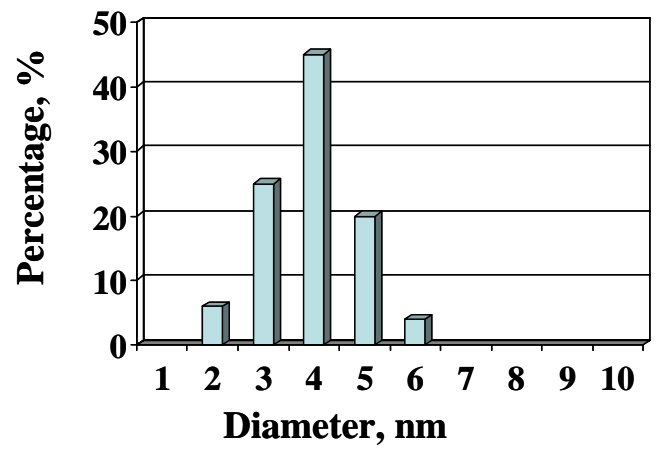


- ${ }^{1} \mathrm{H}$ NMR of $\beta-\mathrm{CD} / \mathrm{CdSe}-\mathrm{CdS}$ after photoactivation

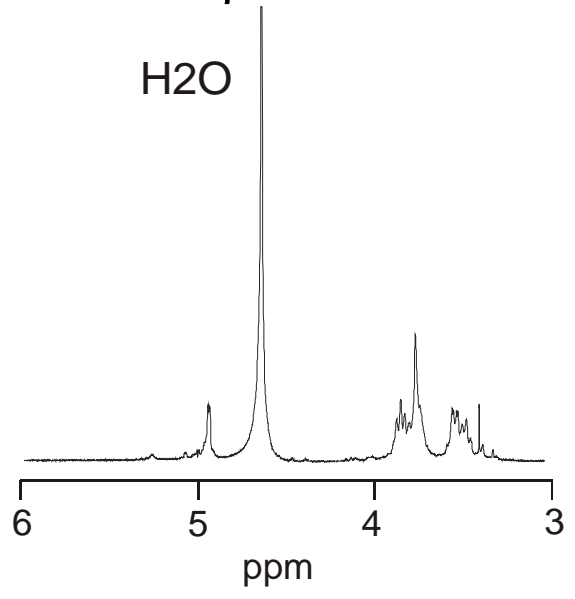

- Electronic absorption spectra of $\beta-\mathrm{CD} / \mathrm{CdSe}$ during the photoactivation.

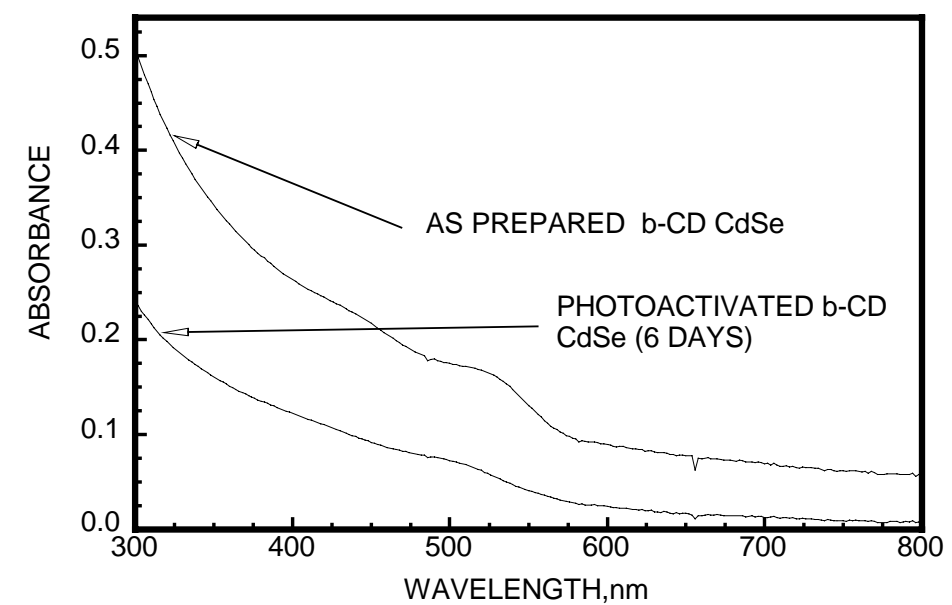

- Electronic absorption spectra of $\beta-\mathrm{CD} / \mathrm{CdSe}-\mathrm{CdS}$ during the photoactivation.

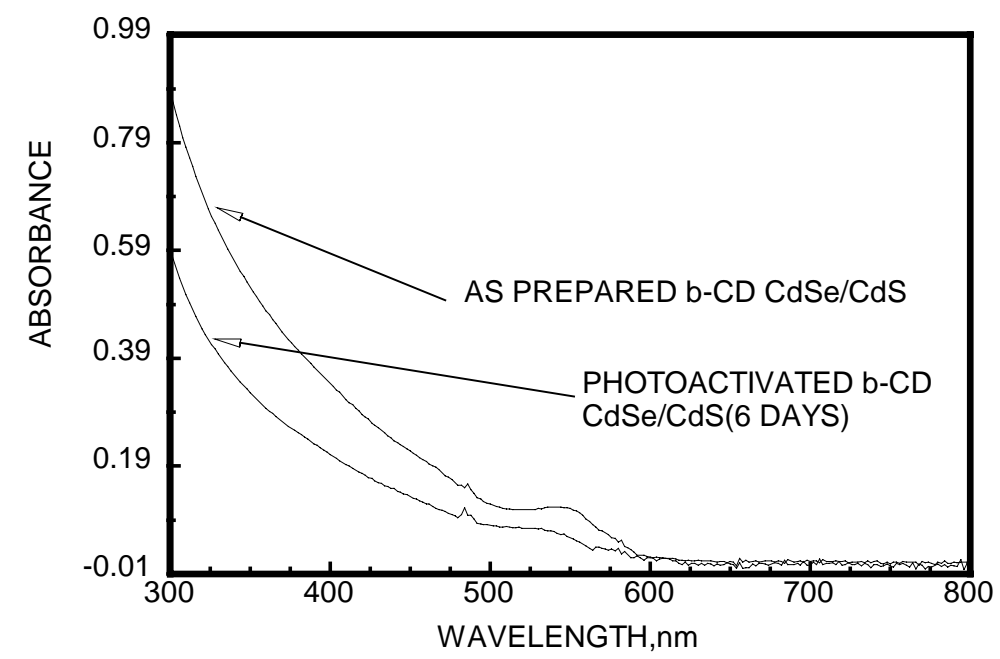

